\title{
Abordaje radial anterógrado en la angiografía selectiva de la mano
}

\section{Anterograde transradial approach for selective hand angiography}

\author{
Agustín Dettbarn'1, Pablo Pedroni², Manuel M. Huamaní Vásquez' ${ }^{1}$, Guillermo Cugat ${ }^{1}$
}

\section{RESUMEN}

El objetivo del caso clínico es demostrar que la punción radial anterógrada es accesible, segura y útil para el tratamiento de la patología vascular de la mano. Presentamos una embolización selectiva de una malformación arteriovenosa con cianoacrilato en una mujer de 58 años que presentaba una tumoración dolorosa en la región metacarpofalángica de la mano izquierda. En el seguimiento a los 6 meses, la paciente persiste asintomática. Hasta donde sabemos, este es el primer reporte de esta técnica. En conclusión, la punción radial anterógrada es una técnica novedosa y útil para realizar diagnóstico e intervenciones terapéuticas de la mano.

Palabras claves: punción radial anterógrada, embolización, malformación arteriovenosa.

\begin{abstract}
The purpose of this clinical case is to demonstrate that the anterograde radial puncture is feasible, safe and useful to treat vascular pathology of the hand. A selective embolization of an arteriovenous malformation with cyanoacrylate is shown in a 59 year old woman symptomatic for a painful tumor in the left hand metacarpophalangeal region. After 6-months follow up, the patient remains asympthomatic. As far as we know, this is the first reported case with such approach. In conclusion, anterograde transradial puncture is a useful technique to make diagnostic and therapeutic interventions in the hand.
\end{abstract}

Key words: anterograde radial puncture, embolization, arteriovenous malformation.

Revista Argentina de Cardioangiología Intervencionista 2016;7(3):145-146

\section{CASO CLÍNICO}

Paciente de sexo femenino, 58 años, sin antecedentes cardiovasculares significativos. Toma en forma ocasional antiinflamatorios no esteroideos.

Motivo de consulta: presenta una tumoración blan$\mathrm{da}$, ligeramente rosada, de bordes irregulares, dolorosa y compresible a la palpación, no pulsátil y con mínimo soplo, de aproximadamente 2 a $3 \mathrm{~cm}$ de diámetro, a nivel de la articulación metacarpofalángica del cuarto dedo de la mano derecha. Dicha tumoración se evidencia tanto en la palma como en el dorso. Refiere su existencia desde hace varios años, pero en los últimos meses ha crecido y se ha tornado dolorosa, impidiéndole realizar sus tareas habituales.

Diagnóstico: con el diagnóstico presuntivo de malformación arteriovenosa (MAV) de alto flujo, se decide realizar una angiografía selectiva de la mano. Analizando las opciones, el abordaje puede realizarse desde diferen-

1. Servicio de Hemodinamia "Sanatorio Argentino". Ciudad de La Plata, Provincia de Buenos Aires.

2. Servicio de Hemodinamia Hospital de alta complejidad "El Cruce". Florencio Varela. Provincia de Buenos Aires.

$\triangle$ Correspondencia: Agustín Dettbarn IServicio de Hemodinamia "Sanatorio Argentino". Calle 56 No 874, B1900BKJ La Plata, Provincia de Buenos Aires, Rep Argentina | Fax: (54-221) 4827906 | adettbarn@hotmail.com tes accesos: a) desde la arteria femoral (punción femoral retrógrada, avanzando cuerda y catéter hasta llegar lo más distalmente posible en la arteria humeral. El inconveniente es que no se pueda llegar selectivamente hasta las arterias radial o cubital, aun utilizando catéteres de $125 \mathrm{~cm}$ de longitud); b) punzando directamente la tumoración (puede que solo se vea el nido o el sector venoso. Recomendado para MAV de bajo flujo); c) por vía radial retrógrada (punción radial convencional; luego de la inyección de contraste, el flujo lo llevará "a contracorriente", plenificando arterias distales y venas. El inconveniente es la menor tinción de los vasos y la posición opuesta del introductor, que impide el tratamiento de la MAV) ${ }^{1}$; d) punción radial anterógrada (no consta su descripción previa). Se procede a realizar esta última, aprovechando la anatomía favorable del antebrazo (delgadez y palpación de la arteria radial hasta un tercio por encima de la muñeca) suponiendo un acceso más directo, con mejor plenificación de los vasos arteriales.

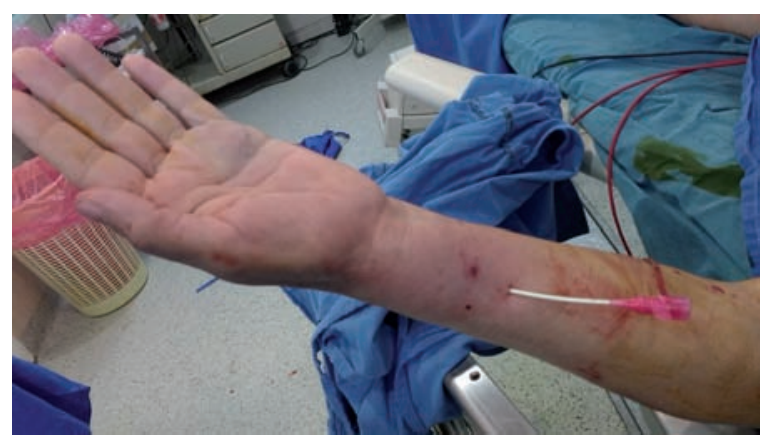

Figura 1. 


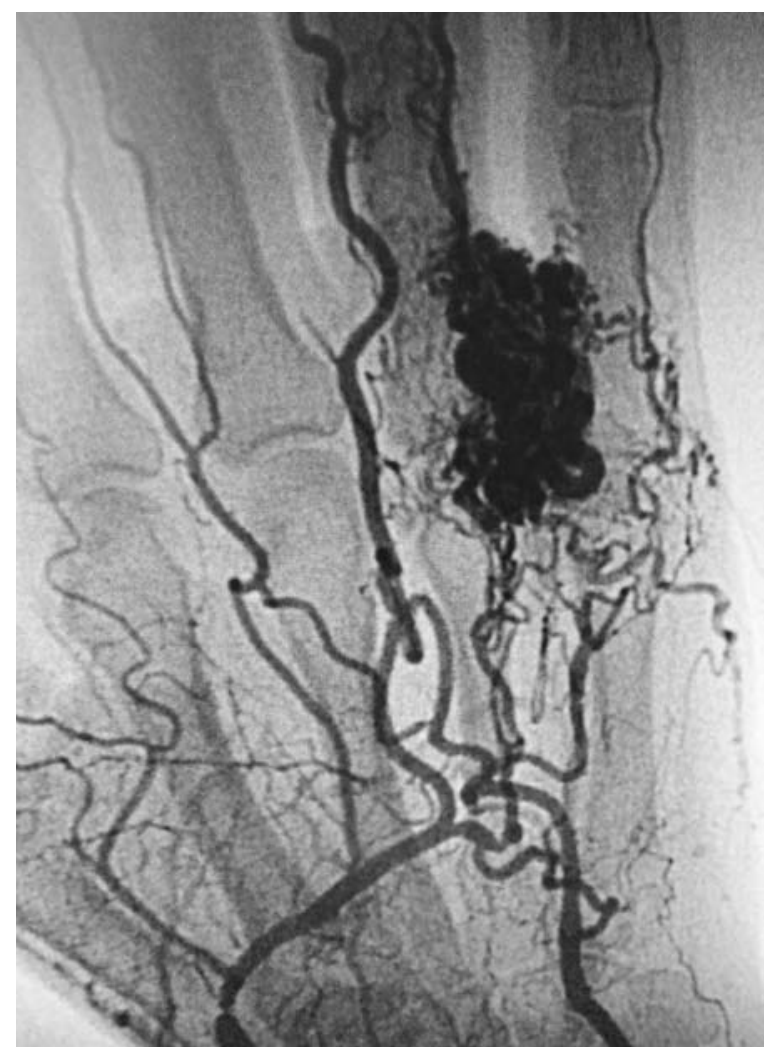

Figura 2.

Técnica: punción de arteria radial anterógrada, a diez o quince $\mathrm{cm}$ de la muñeca, con abbocath $20 \mathrm{G}$ (Figura 1). Pasaje de cuerda Sparta Core 0,014". Introducción parcial de introductor 4F. Infusión de heparina (3000 UI) y nitroglicerina intraarterial. (200 gammas). Inyecciones de contraste no iónico (Optiray). Se observan claramente las arterias radial y cubital, el arco palmar, las arterias metacarpianas y las interfalángicas (nótese la hipertrofia de estas últimas a nivel del 4to dedo y las aferentes de la MAV provenientes del arco palmar y la arteria cubital) (Figura 2). Aprovechando el abordaje anterógrado, se avanza un microcatéter Progreat sobre cuerda 0,014 y se procede a embolizar con cianoacrilato Histoacryl (inyección de $0,5 \mathrm{ml}$, con lavado previo y posterior con solución de dextrosa al 5\%).

\section{RESULTADOS}

Se logra la exclusión parcial, debido a que la MAV también recibe aferentes desde la arteria cubital (Figura

\section{BIBLIOGRAFÍA}

1. Sofocleus CT, Rosen RJ, Raskin K, Fioole B, Hofstee D-J. Congenital malformations of the hand and the forearms. J Endovasc Ther 2001;8:484-94.

2. Alvarez lorio C. Malformaciones congénitas de la mano y antebrazo. Hemodinamia del Sur. Mayo 2003. Revista Argentina de Radiología. Versión on-line ISSN 1852-9992. Rev. argent. radiol. vol.76 no.4 Ciudad Autónoma de Buenos Aires dic. 2012.

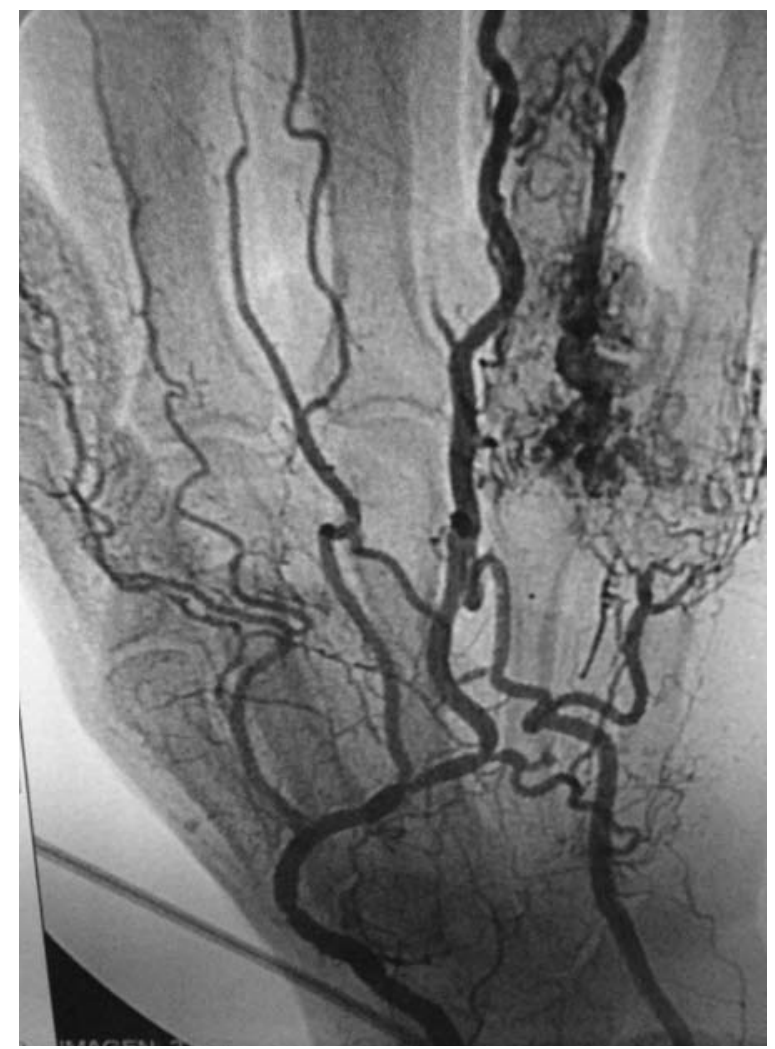

Figura 3.

3). En caso necesario, se programará un nuevo procedimiento en una segunda sesión.

\section{COMENTARIOS}

Hasta donde sabemos, esta es la primera vez que se describe este tipo de acceso ${ }^{1-4}$. Si bien la punción resultó más dificultosa, las imágenes obtenidas son de muy buena calidad y la posición anterógrada de la vaina permite el acceso directo al arco palmar y vasos adyacentes desde la arteria radial distal. El espasmo puede ser convenientemente manejado con nitroglicerina intraarterial. Como vemos, no pudo ser embolizada la totalidad del nido, debido a sus aferentes provenientes de la arteria cubital. Sin embargo, a los seis meses posteriores al procedimiento, la paciente refiere disminución palpable de la masa y ausencia de dolor. Por lo tanto, creemos que, cuando es posible anatómicamente (antebrazo delgado), es un excelente abordaje para realizar estudios diagnósticos y terapéuticos cuando las condiciones lo permitan.

3. Sierre S, Teplisky D, Lipsich J. Malformaciones vasculares: actualización en diagnóstico por imágenes y tratamiento. Arch Argent Pediatr 2016;114(2):167-76.

4. García Mónaco R, Kreindel T, Giachetti A. Malformaciones vasculares: claves diagnósticas para el radiólogo. RAR - Volumen 76 - Número 4 - 2012. 